\title{
A preference to bond? Male prairie voles form pair bonds even in the presence of multiple receptive females.
}

\author{
Tomica D. Blocker ${ }^{\mathrm{a}}$, Alexander G. Ophir ${ }^{\mathrm{b}}$
}

5

\author{
${ }^{a}$ Department of Integrative Biology, Oklahoma State University, Stillwater, OK 74078 \\ ${ }^{\mathrm{b}}$ Department of Psychology, Cornell University, Ithaca, NY 14853
}

Running head: BLOCKER \& OPHIR: MALE VOLES CHOOSE TO BOND

10

Number of words in text: 5,613

Number of figures: 6

\section{Corresponding author:}

15 Alexander G. Ophir

224 Uris Hall

Department of Psychology

Cornell University

Ithaca, NY

2014853 , USA

Tel: (607) 255-3714

FAX: (607) 255-8433

E-mail: ophir@cornell.edu 


\begin{abstract}
Pair bonds are the cornerstone of a monogamous relationship. When individuals of the same species engage in monogamy and promiscuity (i.e., alternative reproductive tactics) it can

5 be difficult to determine which tactic confers greater fitness since measures of fitness can be difficult to ascertain. However, in these circumstances, whether animals preferentially establish pair bonds can reveal decisions that presumably reflect the animals' assessment of how to best maximize reproductive success. In nature, the majority of prairie voles (Microtus ochrogaster) establishes pair bonds and engages in social monogamy while a minority of individuals remains

10 single and presumably mates promiscuously. The existence of these two tactics raises the interesting question: Do bonded male prairie voles choose to 'settle' (for just one partner) or are they preferentially 'settling down'? To determine which of these two tactics is preferred, we provided single male prairie voles simultaneous access to two sexually receptive females for 24 hours and then subsequently tested males in 'partner preference tests' with each female

15 independently contrasted with a novel female. We aimed to determine if males would form a pair bond with one, both, or none of the original females. We found that males formed pair bonds with one of the two females. We also investigated male- and female-initiated aggression and found that during the bonding process, males were more aggressive with females that they did not ultimately form a bond with. In the partner preference tests, males showed more aggression 20 toward unfamiliar females than familiar females. Mismatches in male- and female-initiated aggression suggest that aggressive interactions may be perpetuated more by males than females. Taken together, our data demonstrate that under conditions that are ideal for forgoing bonding and engaging in multiple matings, males choose to establish a pair bond, suggesting that selective pressures may have facilitated bonding by males.
\end{abstract}


Key Words: Microtus ochrogaster, monogamy, partner preference, pair bond, selective aggression

\section{Introduction}

A mating system may be best considered as a collection of individual reproductive tactics that animals within a population adopt at a given time (Clutton-Brock 1989; Emlen \& Oring 1977; Shuster \& Wade 2003). Mating systems should therefore be somewhat plastic because the individual decisions upon which they are built are likely to vary and change. In some instances, individual tactics will begin to follow common patterns, leading to the evolution of one or more

35 alternative reproductive tactic (Oliveira et al. 2008). In these cases, each tactic is associated with its own set of reproductive costs and benefits. When alternative tactics have evolved, there is usually a more common, or bourgeois, form (Oliveira et al. 2008). However, it can be challenging to determine which alternative tactic is preferred. For example, individuals may demonstrate a tendency to engage in the bourgeois tactic (presumably due to greater reproductive

40 success), while the alternative is characterized as making 'the best of a bad job' (Brockmann 2001; Dawkins 1980; Eberhard 1982; Gross 1996; Gross \& Repka 1998a, b; Repka \& Gross 1995). On the other hand, the less common tactic may be 'preferred', where the alternative is thought to be rare because it is costly and allowing only a minority of animals to engage in this behavior (Gross \& Repka 1998a, b; Repka \& Gross 1995; Watters 2005; Young et al. 2013). In a

45 third scenario, the net pay-offs of two tactics might balance out such that each option is equally good over time or contexts (Repka \& Gross 1995; Ryan et al. 1992; Shuster \& Wade 1991). Measures of reproductive success usually provide the best way to disambiguate which tactic is 'preferred', but reproductive success can also be very difficult to quantify (both from a 
theoretical and practical point of view; Arnold \& Wade 1984; Byerly \& Michod 1991; Clutton-

50 Brock 1988). Another way to address this question is to experimentally observe what choices animals make. For example, in a variable mating system (in which some individuals are monogamous and others are not), determining if individuals will choose to establish pairs or mate multiply when they have the option to do either can reveal their natural predispositions and speaks to the selective pressures that shaped behavior in that system.

Although monogamy is a common mating system in many taxa, it is relatively rare among mammals (Kleiman 1977). Indeed, most mammals are polygynous and fit the classic hypothesis that males maximize reproductive success through multiple mating partners (Bateman 1948; Kleiman 1977; Trivers 1972). Social monogamy (a demographic and close sociospatial relationship between a pair, that does not assume exclusive mating; Reichard \& Boesch 2003)

60 accounts for most of the instances of mammalian monogamy. Perhaps the best-known example of non-human mammalian monogamy is the prairie vole, Microtus ochrogaster (Carter \& Getz 1993; Carter \& Keverne 2002; Getz et al. 1981; Getz et al. 1993; Young \& Wang 2004). Research in the lab and field has demonstrated that male and female prairie voles will form strong social preferences with each other (i.e., pair bond) (Getz \& Hofmann 1986; Getz et al.

65 1993; Williams et al. 1992; Winslow et al. 1993), appear to co-defend relatively small and highly convergent areas of space (territories) (Getz et al. 1993; McGuire et al. 2013; Wolff 1985), and will each contribute fairly equally to offspring care (McGuire \& Novak 1984; Solomon 1993; Wang \& Insel 1996; Wang \& Novak 1994). However, we also know that both males and females engage in a non-monogamous mating tactic known as 'wandering', and that paired (a.k.a.,

70 'resident') males and females will engage in extra-pair copulations under naturalistic conditions 
(Getz et al. 1993; McGuire \& Getz 2010; Ophir et al. 2008a; Solomon \& Jacquot 2002; Solomon et al. 2004).

Support for whether the monogamous resident or non-monogamous wanderer tactics are associated with greater reproductive success has been mixed. Some evidence has indicated that 75 monogamous residents are associated with greater fitness (measured over a single breeding cycle), and that selection appears to have eliminated variation in the neural phenotype associated with pair bonding thereby predisposing prairie voles to form pairs (Ophir et al. 2008a; Ophir et al. 2008b; Phelps \& Ophir 2009). Evidence to the contrary is based on data from field studies that have shown that lifetime reproductive success (measured over two or more breeding cycles)

80 is equivocal (Solomon \& Jacquot 2002; Nancy Solomon, personal communication). Similarly, a laboratory study focused on female behavior demonstrated that females readily engage in multimale mating when given access to multiple males over a 24 hour period (Wolff et al. 2002), supporting the notion that 'wandering' (i.e., living singly and mating promiscuously) may be a preferred tactic. Although the evidence appears to support the hypothesis that females prefer to 85 adopt a promiscuous tactic when given the opportunity (Wolff et al. 2002), it is unclear which tactic males prefer, or if they will attempt to mate multiply when given the opportunity.

With these questions in mind, we define mating tactics as the set of decision rules and behaviors that lead to social preferences or a particular living arrangement (c.f., Oliveira et al. 2008). Although there are clear reproductive corollaries, outcomes, and consequences of

90 adopting particular tactics, and social preferences should presumably lead to reproductive behavior, by this definition, a mating tactic need not directly relate to mating behavior. In other words, we use terms like 'mating tactic' to refer to the behaviors that usually lead to mating and reproduction, but that do not necessarily guarantee mating success. The premise of this study is 
to ask if single male prairie voles prefer to form or forgo bonds when circumstances for multiple

95 mating partners are (artificially) ideal. We asked this question because the 'resident' reproductive tactic is not only the most common reproductive tactic in this species, but because bonding is the fundamental component of this tactic and is based on social preference.

To test this question, we gave males access to two sexually receptive females for 24 hours and determined if they demonstrated a preference for one of these two females (Phase I).

100 We also determined if males mated with one or both of them. Next, we tested males in a 'partner preference test' with each of these females (each contrasted with a novel female; Phase II) to determine if males demonstrated a partner preference (i.e., pair bond) for one, both, or none of the females. Several outcomes were possible. For example, considering that males had the opportunity to interact and (presumably) mate with both sexually receptive females in Phase I, if 105 males are predisposed to remain single and mate multiply then they should show no evidence for a pair bond with either female. On the other hand, if males are predisposed to form pair bonds when possible, then they should demonstrate a partner preference for only one of the two females. Yet another possible outcome is that males might show a general predisposition to interact with females from Phase I based on familiarity. In this case, males might either

110 preferentially affiliate with familiar over unfamiliar individuals, or vice versa (i.e., a preference for novel females), regardless of any preferences found in Phase I. Finally, because males become selectively aggressive after forming bonds (Getz \& Hofmann 1986; Winslow et al. 1993), we assessed male aggression directed toward females in each of the two phases of the experiment. In this case, our prediction was that males should become more aggressive toward 115 non-partner females only if (and after) a bond has been established. If males forgo bonding, we expected that aggression toward females would not differ. 


\section{Materials and Methods}

Animals

All animals used in this study were from the F2 generation within a breeding colony derived from wild stock originally trapped in Champagne-Urbana, Illinois. At weaning (21 days), offspring were separated into same-sex litters and housed in polycarbonate cages (29 x 18

$125 \times 13 \mathrm{~cm}$ ) lined with Sani-chip bedding and provided nesting material. No animals in this experiment were raised in isolation. Water and rodent chow (Rodent Chow 5000, Harlan Teklad, Madison, WI, USA) were provided ad libitum and animals were maintained on a 14:10 hr light:dark cycle (lights on at 0600) with ambient temperature maintained at $20 \pm 2^{\circ} \mathrm{C}$. All procedures were approved by the Institutional Animal Care and Use Committee of Oklahoma

130 State University (AS 09-6). All animals included in this study were sexually naïve adults (between 50 and 150 days old) and unrelated to other animals to which they were exposed during the experiment. No animals had been exposed to the opposite sex from the time of weaning to the time they served in the experiment.

135 Phase I: Multi-female mating and pair bond formation test.

We began by exposing male subjects $(N=12)$ to two novel females. Females were matched for age and body mass. We measured mating behavior and behaviors indicative of pair bond formation (see below). Female prairie voles, like many other arvicoline rodents, exhibit 
140 induced estrus and ovulation (Keller 1985), and therefore do not demonstrate the stereotypic estrus cycling seen in most mammals. Prior to experimentation, we induced sexual receptivity in stimulus females by exposing them for 48 hours to soiled bedding and nesting material from unfamiliar males that were unrelated to the subject males (Carter et al. 1980; Dluzen et al. 1981; Richmond \& Stehn 1976). This method robustly and reliably induces estrus and sexual

145 receptivity (i.e., reducing defensive aggression toward males and increasing willingness to mate) in female prairie voles. Using this method enabled us to ensure that all females were in the same sexually receptive state when exposed to study subjects and to time sexual receptivity to occur during both Phases I and II (see below) of this study.

Males were placed in a three chamber apparatus $(60 \times 50 \times 40 \mathrm{~cm})$ consisting of a neutral 150 chamber ( $20 \times 50$ x 40cm), and two smaller adjacent chambers (each $30 \times 25 \times 40 \mathrm{~cm}$ ) (see Ophir \& DelBarco-Trillo 2007). Clean Sani-chip bedding was used to cover the floor of the apparatus. Novel females were tethered in each of the adjacent chambers. Tethering involves using a plastic zip-tie as a collar connected to a light-weight chain attached to the apparatus, and does not inhibit animals from normal activities (e.g., moving, eating, or mating; Ophir et al. 2007; Wolff

$155 \&$ Dunplap 2002). Females were given a 20-minute acclimation period to adjust to the collars following tethering and were observed during this period for discomfort and distress (i.e., excessive or continued scratching at the collar, freezing lasting more than a minute at a time, absence of engaging in normal grooming behavior, locomotion, or chamber exploration). All animals were acclimated (i.e., signs of normal behavior) within 10 minutes and all but four had 160 acclimated within 5 minutes.

After the acclimation period, males were placed in the apparatus in the neutral chamber and recording began. Animals resided in this apparatus for 24 hours. Food and water were 
provided ad libitum within both of the females' chambers and within the neutral chamber, so that males were not required to enter either chamber. This design allowed males to move and interact 165 freely with each female, while limiting interactions between females.

We video recorded Phase I with a Sony SR-120 camcorder (Sony, New York City, NY, USA) placed approximately $1 \mathrm{~m}$ away from the front wall of the apparatus. Recordings were scored using Observer XT software (Noldus Information Technology, Leesburg, VA). Specifically, we counted mating bouts (defined as mounting followed by intromission), time

170 spent in each chamber, time spent in side-by-side contact, number of aggressive events, and initiator of aggressive events (male-to-female and female-to-male aggression). In addition, male and female aggression quotients were calculated to take into account the number of aggressive interactions per the amount of time spent in each respective chamber (number of aggressive events / time spent in the chamber containing that female x 100). Although the full 24 hours of

175 the test were recorded, we only scored the first 3 hours of every trial, along with the first ten minutes of every subsequent hour for all behaviors except mating. This scan sampling allowed us to get a representation of male behavior over the 24-hour period. We scored the full 24-hour videos to ensure we did not miss any mating events between the focal males and either of the two sexually receptive unfamiliar females. We referred to a female from the pair as the 'preferred'

180 female if a male spent at least twice as much time in side-by-side contact with her than with the other ('non-preferred') female.

Phase II: Partner preference tests. 

of the two stimulus females after $24 \mathrm{~h}$ of co-habitation. Williams et al. (1992) demonstrated that 24 hours of cohabitation, even without mating, is sufficient to establish a pair bond. To assess the potential bonds established during Phase I, males participated in a series of two 3-hour 'partner preference' tests. Note that we refer to this test as the 'partner preference' test because this is 190 what it has been called in the literature, but we did not assume that either of the familiar females were actually partners with the male. It was our intent to use this test to determine if either of the two females from Phase I should be considered a bonded 'partner'. We defined a female as a 'partner' if the male spent a majority of time in contact with one of two females (Carter et al. 1995; Carter \& Getz 1993; Insel \& Hulihan 1995; Insel et al. 1995; Williams et al. 1992). The first of two partner preference tests was held in the afternoon immediately following the morning that Phase I ended. Each partner preference test followed a similar design as Phase I, but was comprised of one of the females from Phase I, and a novel stimulus female (matched for age and weight). To avoid the confounding variable of familiarity and scent, partner preference apparatuses were cleaned with soap and water between each test. Clean Sani-chip bedding was 200 used to cover the floor of the apparatus before a test began. In addition, during Phase II, the female from Phase I was placed in the opposite chamber to the one that she inhabited during Phase I, while the novel stimulus female was placed in the chamber that previously housed the familiar female (Figure 1). The second partner preference test was conducted 24 hours after the first partner preference test in exactly the same way except it used the second female from Phase

205 I, and a different unfamiliar stimulus female. Both stimulus females used in the partner preference tests were unrelated to the Phase I females and focal male in each trial. The 
experimenter was blind to whether the females from Phase I were either the 'preferred' or 'nonpreferred' female. The order of the two partner preference tests in Phase II was randomized.

Three-hour recordings were made using a Sony SR-120 camcorder placed approximately

$2101 \mathrm{~m}$ away from the front wall of the apparatus. The three-hour recordings were scored using Observer XT software. Observers were blind to female identity and placement. We quantified the same behaviors as described in Phase I (mating bouts, time spent in each chamber, time spent in side-by-side contact, initiator of aggressive events, number of aggressive events, and aggression quotients).

215

\section{Results}

Phase I: Multi-female mating and pair bond formation test.

We began by assessing single males' responses to multiple sexually receptive females by focusing on measures of social and sexual contact. One male was excluded from the analysis $(N$ $=11$ ) due to experimenter error. All males preferred one female of the two, and ten of eleven males spent at least twice as much time in side-by-side contact with one female over the other (Exact binomial test, (two-tailed) $P=0.01$ ), significantly more often than would be expected by

225 chance. Not surprisingly, males spent significantly more time in side-by-side contact with preferred females, compared to non-preferred females (two-tailed Wilcoxon signed rank test: $W$ $=66, N=11, P=0.001$, Figure $2 a$ ). Also not surprisingly, males spent more time in the chamber containing the preferred females $(W=66, N=11, P=0.001$, Figure $2 \boldsymbol{b})$. 
We quantified the number of mating bouts for the full 24-hour test to assess mating. Five

230 of eleven males mated. Mating only occurred with females that we later determined to be preferred females, and we therefore used a one-tailed Wilcoxon signed rank test here. Not surprisingly, males mated significantly more with the preferred females $(W=15, N=11, P=$ 0.03 , Figure $2 c$ ). Similarly, the number of mounts, the time spent intromitting that was not followed by genital grooming, and the time spent intromitting that was followed by genital 235 grooming were all significantly greater with preferred females than non-preferred females (all $W^{\prime} s=15, N$ 's $=11, P$ 's $=0.03$ ). Because the nonparametric data produced identical results, we also report two-tailed t-tests for each of the aforementioned comparisons for reference only (Mating bout: $\mathrm{t}_{10}=2.77, P=0.02$; Mounts: $\mathrm{t}_{10}=2.50, P=0.03$; Intromission without genital grooming: $\mathrm{t}_{10}=2.20, P=0.05$; Intromission with genital grooming: $\mathrm{t}_{10}=2.78, P=0.02$ ).

240 We first investigated aggression by comparing the number of aggressive encounters the male initiated with each female, and the number of aggressive encounters initiated by each female toward the male. By this measure, males initiated the same number of aggressive encounters toward preferred and non-preferred females $(W=-12, N=11, P=0.51$, Figure 3a), and females initiated the same number of aggressive encounters toward males $(W=15, N=11, P$

$245=0.53$, Figure $3 \boldsymbol{b})$. However, because males spent more time in proximity to preferred females than non-preferred females, the probability of engaging in any interaction was higher with preferred females. We therefore normalized aggression toward each female based on the time spent in the chamber containing a female (i.e., number of aggressive encounters / total time in chamber $x$ 100). Analyzing the data in this way revealed that males were relatively more 250 aggressive toward non-preferred females than preferred females $(W=-39, N=11, P=0.02$, Figure 3c). Similarly, non-preferred females directed more aggression toward males than the 
preferred females did ( $W=-46, N=11, P=0.04$, Figure $3 d)$. Although aggression initiated by both females was not significantly different from the aggression that males initiated toward females, females tended to initiate more aggressive encounters in both absolute $(W=-39, N=11$, $255 P=0.09)$ and relative aggressive encounters $(W=-38, N=11, P=0.10)$.

\section{Phase II: Partner preference tests.}

In Phase II we used partner preference tests to evaluate whether males showed evidence

260 for a pair bond with either the preferred or non-preferred female when each was independently contrasted with a novel female. Three possible outcomes were expected (see Introduction): 1) that males would show no evidence for a pair bond with either female, 2) that males would demonstrate a partner preference for only one of the two females, or 3) that males would show a general predisposition to interact with females from Phase I based on familiarity. To test these

265 potential outcomes, we compared the time in side-by-side contact with the preferred female or a sexually receptive novel (unfamiliar) female, and with the non-preferred female or a sexually receptive novel female. As before we also compared aggression (absolute and relative) for each partner preference test in Phase II. No mating bouts were observed in either 3-hour test.

Our results indicate that males demonstrated a partner preference for preferred females 270 from Phase I (two-tailed Wilcoxon signed rank test: $W=46, N=11, P=0.04$, Figure 4a), but not for non-preferred females $(W=6, N=11, P=0.83$, Figure $4 \boldsymbol{b})$. Similarly, males spent more time in the chamber with his preferred female over a novel female ( $W=46, N=11, P=0.04$, Figure $4 c)$ but not for non-preferred females compared to novel females $(W=-14, N=11, P=$ 0.58, Figure $4 d$ ). These data indicate that familiarity does not produce preferences (males did 
275 not consistently prefer Phase I females to the novel females with which they were contrasted). More importantly, these results indicate that even when given access to two sexually receptive females, males will form bonds with only one female, and this bond persists over different testing bouts (Phase I and Phase II).

Next we compared the number of aggressive encounters initiated by males in the partner 280 preference tests comparing the preferred female with a novel female, and the non-preferred female with a novel female. Like during Phase I, actual numbers of aggressive encounters did not significantly differ between paired and novel females $(W=-12, N=11, P=0.35$, Figure 5a). However unlike before, males initiated significantly more aggression with novel females over the non-preferred females $(W=-42, N=11, P=0.02$, Figure $5 \boldsymbol{b})$. When we accounted for the

285 total amount of time that males spent in the vicinity of females in each of these choice tests (time in chamber), we found that males initiated significantly more aggression with each novel female over either the preferred or non-preferred female (Preferred female: $W=-30, N=11, P=0.04$; Non-Preferred female $W=-37, N=11, P=0.03$, Figure $5 \boldsymbol{d}, \boldsymbol{e})$. Furthermore, the degree of actual aggression and relative aggression males directed toward preferred and non-preferred 290 females did not differ (Mann Whitney U Test; Actual Aggression: $U=60, P=1.0$; Relative Aggression: $U=59.5, P=0.97$, Figure $5 \boldsymbol{c}, \boldsymbol{f})$. These results indicate that although males were more aggressive toward non-preferred females in Phase I, male aggressive behavior toward nonpreferred females appeared to be diminished in Phase II. The results also show that familiarity appears to influence male initiated aggression, with males engaging in more aggressive 295 encounters with unfamiliar (novel) females.

Consistent with the male-initiated aggression, females in the preferred vs. novel preference test initiated the same number of aggressive encounters toward males $(W=-22, N=$ 
11, $P=0.35$, Figure $6 \boldsymbol{a}$ ), but the novel females initiated more relative aggression compared to preferred females $(W=-58, N=11, P=0.007$, Figure $\boldsymbol{6} \boldsymbol{d})$. However, unlike male-initiated aggression, non-preferred and novel females showed no difference in absolute or relative aggression directed toward males $(W=-31, N=11, P=0.18 ; W=-38, N=11, P=0.10 ;$ Figure $\boldsymbol{\sigma} \boldsymbol{b}, \boldsymbol{e}$, respectively). Finally, preferred and non-preferred females did not initiate aggression toward the male differently (Mann Whitney U Test; Actual Aggression: $U=55.5, N=11, P=$ 0.76; Relative Aggression: $U=57.5, N=11, P=0.87$, Figure $\boldsymbol{\sigma} \boldsymbol{c}, \boldsymbol{f})$. Taken together, the data

305 indicate that despite males initiating more aggression toward unfamiliar females, the novel females do not necessarily reciprocate the same degree of aggression (at least when contrasted with non-preferred females).

\section{Discussion}

We have demonstrated that single prairie vole males appear to preferentially form pair bonds, even when conditions are ideal for refraining from bonding and pursuing multiple mates without social restriction. Furthermore, we have shown that during the bonding process (Phase I), males demonstrate relatively more aggression toward females with which they do not bond

315 than the females with which they ultimately do bond. Males also show relatively more aggression toward unfamiliar females than familiar females (Phase II). The amount of aggression initiated by females toward males usually matched the amount of aggression males initiated toward females. However, this was not true for non-preferred and novel females; males initiated significantly more relative and actual aggression toward novel females, whereas the aggression 
320 that novel and non-preferred females initiated did not differ, suggesting that aggressive interactions may be perpetuated more by males than females.

Are male prairie voles predisposed to bond?

Ophir et al. (2008b) demonstrated that bonded ('resident') males fertilized more embryos (with or without their partner) than non-bonded 'wanderers'. They also showed that neural mechanisms in brain structures that are necessary and sufficient for forming pair bonds were ubiquitous in animals whether or not they formed a bond. These results led to the conclusion that the pair bonded 'resident' tactic was the preferred route to maximize reproductive success, an

330 idea supported by others (McGuire \& Getz 2010). However, some have argued that remaining single is a preferred route toward maximizing reproductive success (McGuire et al. 2013; Solomon \& Jacquot 2002). This hypothesis is certainly in line with classic theory indicating that males maximize reproductive success though multiple mating (Andersson 1994; Bateman 1948; Kleiman 1977; Trivers 1972). It is also supported by the observation that non-bonded wanderers

335 had larger body sizes (Solomon \& Jacquot 2002), indicating that wanderers might be more competitive. In contrast, we have not found this body size relationship, and tended to find the reverse (Ophir et al. 2008b). Furthermore, Ophir \& DelBarco-Trillo (2007) showed that not only did females prefer males with larger ano-genital distances (AGD; a marker of competitiveness in many rodent species) in the lab, but paired 'resident' males had larger AGDs than single

340 'wanderers' under semi-natural field conditions. These conflicting results have made it difficult to determine which, if either, tactic is most competitive and/or best for maximizing fitness. 
In the context of a discussion considering fitness consequences, is it important to remember that bonding and mating are not interchangeable concepts and that pair bonding does not preclude individuals from mating with individuals outside the pair. For example, bonded

345 males investigate sexually receptive females more than their mates (Parker et al. 2011;

Rodriguez et al. 2013). Moreover, we know that some proportion of males and females engage in extra-pair mating (Ophir et al. 2008a). Therefore, the initial preference to affiliate with only one female that we found may be transient (but see Resendez \& Aragona 2013).

Nevertheless, bonding is an inherent and necessary step toward residency. It is

350 noteworthy that our design was artificially 'ideal' for remaining single and multiple mating, and was not complicated by impediments that males might experience in nature like interference from other males or the ability of females to run away. In spite of this, our study showed that males actively choose to bond when given the opportunity, and they exclusively mate with the preferred female during or shortly after the bonding process if they mate at all. Whether this

355 social preference to bond is a viable means toward maximizing reproductive success remains an open question, although some of our previous work suggests it might be (Ophir et al. 2008a). It is important to point out that the data from this work, which was conducted in semi-natural outdoor enclosures, were limited in that they focused on a single reproductive cycle and did not account for survival of offspring. It is unknown if forming bonds and engaging in the resident tactic has

360 greater lifetime reproductive success over single wanderers. Some data appear to support the hypothesis that residents and wanderers have equal reproductive success over a longer time-scale (Nancy Solomon, personal communication), raising questions about whether either type of male is making the 'best of a bad job' (Solomon \& Jacquot 2002). In the absence of more conclusive fitness data, and in the context that male prairie voles appear to prefer to pair bond with one 
365 female, we believe the majority of evidence supports our hypothesis that residency (which by definition requires bonding) is a preferred tactic and that selection has biased male prairie voles to form bonds. However, more work is necessary to fully substantiate this hypothesis.

What does aggression tell us about bonding and familiarity?

Winslow et al. (1993) showed that male prairie voles are highly aggressive toward strangers - but not their partners - once the pair bond has been established. In contrast they demonstrated that males are relatively unaggressive with strangers before they form a bond. Our data indicate that as the pair bond was forming, males were relatively more aggressive toward

375 non-preferred females compared to the preferred females (i.e., the females we later determined were pair bonded with males). Our data suggest that males quickly become selectively aggressive to females during the earliest stages of pair bond formation, and possibly before the pair bond has been established.

Several pieces of evidence from our study hint that males were the prime source of the 380 aggression. First, males were more often the first to attack in interactions between males and non-preferred females. Furthermore, both novel and non-preferred females initiated equal amounts of aggression toward males. Despite this, males initiated more aggression with novel females than the non-preferred females in Phase II, suggesting that aggression between males and females is not tit-for-tat. If females were the prime instigators of aggressive encounters, then

385 males should be expected to proportionately respond to female aggression, and it appears that this is not the case. Finally, female sexual receptivity was induced, presumably increasing their motivation to affiliate positively with males. 
We believe our data indicate that males were the primary instigator of the aggressive interactions (see above). However, non-preferred females were more aggressive toward males

390 than preferred females were toward males. It is therefore possible that males ultimately bonded with the less aggressive female because they were avoiding the more aggressive (non-preferred) female. This interpretation runs counter to the evidence discussed immediately above, but it raises an important set of questions: 1) were males responding to female initiated aggression, 2) were females responding to male initiated aggression, or 3) was the heightened aggression a 395 consequence of an interaction between aggression initiated by each animal? Unfortunately, it is difficult to disambiguate these possibilities. For example, it is difficult to know if aggression initiated by the non-preferred female is independent of the male's previous behavior (e.g., a preemptive defensive retaliation resulting from recent aggression initiated by the male) or overt offensive aggression.

400 Our study also showed that bonded males are more aggressive toward unfamiliar females. Although we found that familiarity does not produce preferences, our results are consistent with others that indicate that familiarity decreases aggressive behavior in prairie voles (Firestone et al. 1991). Several possibilities could explain why male prairie voles initiated more aggression toward unfamiliar females (e.g., threat of infanticide, territoriality, etc). Whatever the reason, it is 405 interesting to consider that under natural conditions males might be more likely to engage in extra-pair mating with familiar neighbors over unfamiliar neighbors because they are less likely to deter familiar neighbors with aggressive encounters. To our knowledge this prediction has not been tested.

410 Possible insight into the evolution of monogamy in prairie voles. 
At face value, our data show males prefer to bond, and at least initially, they do not mate multiply. Females, on the other hand, appear to readily engage in promiscuous mating when given access to multiple males over a $24 \mathrm{~h}$ period (Wolff et al. 2002). These combined results 415 may shed light on why social monogamy might have evolved in prairie voles. Conventional thought suggests that males benefit most from mating with multiple females, leading to intense and costly competition among males for access to females resulting in uneven mating success among males (Andersson 1994; Bateman 1948; Clutton-Brock \& Vincent 1991; Emlen \& Oring 1977; Shuster \& Wade 2003; Trivers 1972). One way (social) monogamy may evolve is when

420 the energetic costs of defending resources become too great to effectively fertilize multiple females (Clutton-Brock 1989; Clutton-Brock \& Vincent 1991; Emlen \& Oring 1977; Komers \& Brotherton 1997; Orians 1969; Ostfeld 1985, 1990; Reichard \& Boesch 2003; Shuster \& Wade 2003). In this context, males will reduce effort from attempting to monopolize several females, to guarding or sustaining just one. Forming a bond presumably increases the probability that a 425 male will sire some proportion of offspring, although this will obviously depend on the male's individual ability to mate guard (refs Op cit.). Interestingly, this theory suggests that male tactics provide the pressure toward monogamy (i.e., 'male-imposed monogamy').

There are obviously other equally valid routes for monogamy to evolve (e.g., need for biparental care, extreme ecological constraints on males and females, etc; Clutton-Brock 1989;

430 Clutton-Brock \& Vincent 1991; Emlen \& Oring 1977; Gubernick \& Teferi 2000; Komers \& Brotherton 1997; Orians 1969; Ostfeld 1985, 1990; Reichard \& Boesch 2003; Shuster \& Wade 2003; Wolff \& Macdonald 2004). However, unlike 'male-imposed monogamy', these other routes to monogamy do not predict that (1) males should benefit from bonding, while (2) benefits 
to females from either bonding or remaining single should be equivocal. Although we are

435 unaware of studies investigating the predisposition for females to bond, the evidence showing that females readily mate multiply (Wolff et al. 2002) while males under similar conditions do not and will choose to pair bond (current study) hints that monogamy in prairie voles may have followed a male-imposed path.

Retrospectively replicating the steps of evolution in this (or any) species is impossible.

440 However, looking for behavioral tendencies and predispositions, particularly when male and female behaviors are misaligned, provides insight into the process. Prairie voles are clearly a good example of social monogamy, however, it is not clear how or why this mating system might have evolved. The data from our study provide the basis for some speculation on these fundamental questions.

\section{Acknowledgements:}

We wish to thank the four anonymous reviewers, whose constructive comments improved this paper. We thank Asad Rehman and Josh Garner for their help collecting behavioral data from

450 video recordings. This work was supported by funding from the National Science Foundation Graduate Research Fellowship to T.D.B. (2010103297) and by the Eunice Kennedy Shriver National Institute of Child Health and Human Development to A.G.O. (HD065604).

\section{Figure Captions}


Figure 1: Experimental design. Phase I: Initial exposure of male to two sexually receptive females, lasting 24 hours. Phase II: Subsequent partner preference tests contrasting each female from Phase I (A and B) with a unique novel female $\left(\mathrm{N}_{1}\right.$ and $\left.\mathrm{N}_{2}\right)$.

460 Figure 2: A) Mean \pm SE time (in minutes) that single males spent in side-by-side (SxS) contact with each sexually receptive female in 24 hours. Females with which males spent more time in SxS contact were called the 'preferred' females; females with which males spent less time in $\mathrm{SxS}$ contact were called the 'non-preferred' females. B) Mean \pm SE time (in minutes) that single males spent in the chamber housing each sexually receptive female in 24 hours. C) Mean \pm SE

465 time (in minutes) males spent mating with each sexually receptive female in 24 hours. Here, mating is defined as the time from initial mount to completion of intromission (with or without subsequent genital grooming). Lines between bars represent individual data. $* * * P \leq 0.001 ; * P$ $\leq 0.5$.

470 Figure 3: A) Mean \pm SE number of observed aggressive events that single males initiated toward the 'preferred' and 'non-preferred' females (see text for definitions) in 24 hours. B) Mean \pm SE number of observed aggressive events that the 'preferred' and 'non-preferred' females initiated toward the males in 24 hours. C) Mean \pm SE relative aggression (number of aggressive events / time in the chamber containing the female $\mathrm{x}$ 100) that single males initiated toward the

475 'preferred' and 'non-preferred' females in 24 hours. D) Mean \pm SE relative aggression that the 'preferred' and 'non-preferred' females initiated toward the males in 24 hours. Lines between bars represent individual data. $* P \leq 0.05 ; n s=$ not significant. 
Figure 4: A) Mean \pm SE time (in minutes) that single males spent in side-by-side $(\mathrm{SxS})$ contact 480 with the preferred female or a sexually receptive novel female in a 3-hour partner preference test. B) Mean $\pm \mathrm{SE}$ time (in minutes) that single males spent in $\mathrm{SxS}$ contact with the non-preferred female or a sexually receptive novel female in a 3-hour partner preference test. C) Mean \pm SE time (in minutes) that single males spent in the chamber housing the preferred or novel female. D) Mean \pm SE time (in minutes) that single males spent in the chamber housing the non485 preferred or novel female. Lines between bars represent individual data. $* \leq 0.05$; $n s=$ not significant.

Figure 5: A) Mean \pm SE number of observed aggressive events that single males initiated toward the preferred female or a sexually receptive novel female in a 3-hour partner preference 490 test. B) Mean \pm SE number of observed aggressive events that single males initiated toward the non-preferred female or a sexually receptive novel female in a 3-hour partner preference test. C) Mean \pm SE number of observed aggressive events that single males initiated toward the preferred or non-preferred females in their respective 3-hour partner preference tests. D) Mean $\pm \mathrm{SE}$ relative aggression (number of aggressive events / time in the chamber containing the female $\mathrm{x}$ 495 100) that single males initiated toward the preferred female or a sexually receptive novel female in a 3-hour partner preference test. E) Mean \pm SE relative aggression that single males initiated toward the non-preferred female or a sexually receptive novel female in a 3-hour partner preference test. F) Mean \pm SE relative aggression that single males initiated toward the preferred or non-preferred females in their respective 3-hour partner preference tests. Lines between bars 500 represent individual data; panels $\mathrm{c}$ and $\mathrm{f}$ do not represent repeated measures. $* P \leq 0.05 ; n s=$ not significant. 
Figure 6: A) Mean \pm SE number of observed aggressive events that the preferred female or a sexually receptive novel female initiated toward single males in a 3-hour partner preference test. B) Mean \pm SE number of observed aggressive events that the non-preferred female or a sexually

505 receptive novel female initiated toward single males in a 3-hour partner preference test. C) Mean \pm SE number of observed aggressive events that the preferred or non-preferred females initiated toward single males in their respective 3-hour partner preference tests. D) Mean \pm SE relative aggression (number of aggressive events / time in the chamber containing the female $\mathrm{x}$ 100) that the preferred female or a sexually receptive novel female initiated toward single males in a 3-

510 hour partner preference test. E) Mean \pm SE relative aggression that the non-preferred female or a sexually receptive novel female initiated toward single males in a 3-hour partner preference test. F) Mean \pm SE relative aggression that the preferred or non-preferred females initiated toward single males in their respective 3-hour partner preference tests. Lines between bars represent individual data; panels $\mathrm{c}$ and $\mathrm{f}$ do not represent repeated measures. $* * P \leq 0.01 ; n s=$ not 515 significant.

\section{References}

520 Andersson, M. 1994. Sexual Selection. Princeton, New Jersey: Princeton University Press.

Arnold, S. J. \& Wade, M. J. 1984. On the measurement of natural and sexual selection: Applications. Evolution, 38, 720-734.

Bateman, A. J. 1948. Intra-sexual selection in Drosophila. Heredity, 2, 349-368. 
Brockmann, H. J. 2001. The evolution of alternative strategies and tactics. In: Advances in the Study of Behavior (Ed. by P. J. B. Slater, J. S. Rosenblatt, C. T. Snowdon \& T. J. Roper), pp. 1-151. New York: Academic Press.

Byerly, H. C. \& Michod, R. E. 1991. Fitness and evolutionary explanation. Biology and Philosophy, 6, 1-22.

Carter, C. S., DeVries, A. C. \& Getz, L. L. 1995. Physiological substrates of mammalian monogamy: The prairie vole model. Neuroscience and Biobehavioral Reviews, 19, 303314.

Carter, C. S. \& Getz, L. L. 1993. Monogamy and the prairie vole. Scientific American, 268, 100-106.

Carter, C. S., Getz, L. L., Gavish, L., McDermott, J. L. \& Arnold, P. 1980. Male related

535 pheromones and the activation of female reproduction in the prairie vole (Microtus ochrogaster). Biology of Reproduction, 23, 1038-1045.

Carter, C. S. \& Keverne, E. B. 2002. The neurobiology of social affiliation and pair bonding. In: Hormones, Brain and Behavior (Ed. by D. Pfaff), pp. 299-337. San Diego: Academic Press.

540 Clutton-Brock, T. H. 1988. Reproductive success: Studies of individual variation in contrasting breeding systems. London: Chicago University Press.

Clutton-Brock, T. H. 1989. Mammalian mating systems. Proceedings of the Royal Society of London Series B-Biological Sciences, 236, 339-372.

Clutton-Brock, T. H. \& Vincent, A. C. J. 1991. Sexual selection and the potential reproductive rates of males and females. Nature, 351, 58-60. 
Dawkins, R. 1980. Good strategy or evolutionarily stable strategy? In: Sociobiology: beyond nature/nurture? (Ed. by J. Silverberg), pp. 331-367. Boulder, Colarado: Westview Press.

Dluzen, D. E., Ramirez, V. D., Carter, C. S. \& Getz, L. L. 1981. Male vole urine changes luteinizing-hormone-releasing hormone and norepinephrine in female olfactory-bulb. $550 \quad$ Science, 212, 573-575.

Eberhard, W. G. 1982. Beetle horn dimorphism - making the best of a bad lot. American Naturalist, 119, 420-426.

Emlen, S. T. \& Oring, L. W. 1977. Ecology, sexual selection, and evolution of mating systems. Science, 197, 215-223.

555 Firestone, K. B., Thompson, K. V. \& Carter, C. S. 1991. Female-female interactions and social stress in prairie voles. Behavioral and Neural Biology, 55, 31-41.

Getz, L. L., Carter, C. S. \& Gavish, L. 1981. The mating system by the prairie vole, Microtus ochrogaster: Field and laboratory evidence for pair-bonding. Behavioral Ecology and Sociobiology, 8, 189-194.

560 Getz, L. L. \& Hofmann, J. E. 1986. Social organization in free-living prairie voles, Microtus ochrogaster. Behavioral Ecology and Sociobiology, 18, 275-282.

Getz, L. L., McGuire, B., Pizzuto, T., Hofmann, J. \& Frase, B. 1993. Social organization of the prairie vole (Microtus ochrogaster). Journal of Mammalogy, 74, 44-58.

Gross, M. R. 1996. Alternative reproductive strategies and tactics: Diversity within sexes. 565 Trends in Ecology and Evolution, 11, 92-98.

Gross, M. R. \& Repka, J. 1998a. Inheritance in the conditional strategy. In: Game Theory and Animal Behavior (Ed. by L. A. Dugatkin \& H. K. Reeve), pp. 168-187. Oxford, UK: Oxford University Press. 
Gross, M. R. \& Repka, J. 1998b. Stability with inheritance in the conditional strategy. Journal of Theoretical Biology, 192, 445-453.

Gubernick, D. J. \& Teferi, T. 2000. Adaptive significance of male parental care in a monogmaous mammal. Proceedings of the Royal Society of London Series B-Biological Sciences, 267, 147-150.

Insel, T. R. \& Hulihan, T. J. 1995. A gender-specific mechanism for pair bonding: Oxytocin 575 and partner preference formation in monogamous voles. Behavioral Neuroscience, 109, 782-789.

Insel, T. R., Preston, S. \& Winslow, J. T. 1995. Mating in the monogamous male: Behavioral consequences. Physiology and Behavior, 57, 615-627.

Keller, B. L. 1985. Reproductive patterns. In: Biology of New World Microtus (Ed. by R. H. Tamarin), pp. 725-778. Lawrence, Kansas: Allen Press.

Kleiman, D. G. 1977. Monogamy in mammals. Quarterly Review of Biology, 52, 39-69.

Komers, P. E. \& Brotherton, P. N. M. 1997. Female space use is the best predictor of monogamy in mammals. Proceedings of the Royal Society of London Series B-Biological Sciences, 264, 1261-1270.

585 McGuire, B. \& Getz, L. L. 2010. Alternative male reproductive tactics in a natural population of prairie voles Microtus ochrogaster. Acta Theriologica, 55, 261-270.

McGuire, B., Getz, L. L., Bemis, W. E. \& Oli, M. K. 2013. Social dynamics and dispersal in free-living prairie voles (Microtus ochrogaster). Journal of Mammalogy, 94, 40-49.

McGuire, B. \& Novak, M. 1984. A comparison of maternal behaviour in the meadow vole (Microtus pennsylvanicus), prairie vole (M. ochrogaster) and pine vole (M. pinetorum). Animal Behaviour, 32, 1132-1141. 
Oliveira, R. F., Taborsky, M. \& Brockmann, H. J. 2008. Alternative Reproductive Tactics: An Integrative Approach. New York: Cambridge University Press.

Ophir, A. G. \& DelBarco-Trillo, J. 2007. Anogenital distance predicts female choice and male 595 potency in prairie voles. Physiology and Behavior, 92, 533-540.

Ophir, A. G., Phelps, S. M., Sorin, A. B. \& Wolff, J. O. 2007. Morphological, genetic, and behavioral comparisons of two prairie vole populations in the field and laboratory. Journal of Mammalogy, 88, 989-999.

Ophir, A. G., Phelps, S. M., Sorin, A. B. \& Wolff, J. O. 2008a. Social but not genetic 600 monogamy is associated with greater breeding success in prairie voles. Animal Behaviour, 75, $1143-1154$.

Ophir, A. G., Wolff, J. O. \& Phelps, S. M. 2008b. Variation in neural V1aR predicts sexual fidelity and space use among prairie voles in semi-natural settings. Proceedings of the National Academy of Sciences, USA, 105, 1249-1254.

605 Orians, G. H. 1969. On evolution of mating systems in birds and mammals. American Naturalist, 103, 589-603.

Ostfeld, R. S. 1985. Limiting resources and territoriality in microtine rodents. American Naturalist, 126.

Ostfeld, R. S. 1990. The ecology of territoriality in small mammals. Trends in Ecology and Evolution, 5, 411-415.

Parker, J. T., Rodriguez, N., Lawal, B., Delevan, C. J. \& Bamshad, M. 2011. Mating increases male's interest in other females: A cognitive study in socially monogamous prairie voles (Microtus ochrogaster). Behavioural Processes, 88, 127-134. 
Phelps, S. M. \& Ophir, A. G. 2009. Monogamous brains and alternative tactics: Neuronal

615 V1aR, space use and sexual infidelity among male prairie voles. In: Cognitive Ecology II (Ed. by Dukas R. \& Ratcliffe J.M.), pp. 156-176. Chicago: University of Chicago Press.

Reichard, U. H. \& Boesch, C. 2003. Monogamy: Mating strategies and partnerships in birds, humans and other mammals. Cambridge: Cambridge University Press.

Repka, J. \& Gross, M. R. 1995. The evolutionarily stable strategy under individual condition and tactic frequency. Journal of Theoretical Biology, 176, 27-31.

Resendez, S. L. \& Aragona, B. J. 2013. Aversive motivation and the maintenance of monogamous pair bonding. Reviews in the Neurosciences, 24, 51-60.

Richmond, M. E. \& Stehn, R. A. 1976. Olfaction and reproductive behavior in microtine rodents. In: Mammalian olfaction, reproductive processess and behavior (Ed. by R. L. Doty), pp. 197-217. New York: Academic Press.

Rodriguez, N. A., Legzim, K. M., Aliou, F., Al-Naimi, O. A. S. \& Bamshad, M. 2013. Does mating prevent monogamous males from seeking other females? A study in prairie voles (Microtus ochrogaster). Behavioural Processes, 100, 185-191.

Ryan, M. J., Pease, C. M. \& Morris, M. R. 1992. A genetic polymorphism in the swordtail Xiphophorus nigrensis: Testing the prediction of equal fitnesses. American Naturalist, 139, 21-31.

Shuster, S. M. \& Wade, M. J. 1991. Equal mating success among male reproductive strategies in a marine isopod. Nature, 350, 608-610.

Shuster, S. M. \& Wade, M. J. 2003. Mating Systems and Strategies. Princeton: Princeton University Press. 
Solomon, N. G. 1993. Comparison of parental behavior in male and female prairie voles (Microtus ochrogaster). Canadian Journal of Zoology, 71, 434-437.

Solomon, N. G. \& Jacquot, J. J. 2002. Characteristics of resident and wandering prairie voles, Microtus ochrogaster. Canadian Journal of Zoology, 80, 951-955.

640 Solomon, N. G., Keane, B., Knoch, L. R. \& Hogan, P. J. 2004. Multiple paternity in socially monogamous prairie voles (Microtus ochrogaster). Canadian Journal of Zoology, 82, 1667-1671.

Trivers, R. 1972. Parental investment and sexual selection. In: Sexual selection and the descent of man (Ed. by B. Campbell), pp. 136-179. Chicago: Aldine Press.

645 Wang, Z. \& Insel, T. R. 1996. Parental behavior in voles. Advances in the Study of Behavior, 25, 361-383.

Wang, Z. X. \& Novak, M. A. 1994. Parental care and litter development in primiparous and multiparous prairie voles (Microtus ochrogaster). Journal of Mammalogy, 75, 18-23.

Watters, J. V. 2005. Can the alternative male tactics 'fighter' and 'sneaker' be considered 'coercer' and 'cooperator' in coho salmon? Animal Behaviour, 70, 1055-1062.

Williams, J. R., Catania, K. C. \& Carter, C. S. 1992. Development of partner preference in female prairie voles (Microtus ochrogaster): The role of social and sexual experience. Hormones and Behavior, 26, 339-349.

Winslow, J. T., Hastings, N., Carter, C. S., Harbaugh, C. R. \& Insel, T. R. 1993. A role for central vasopressin in pair bonding in monogamous prairie voles. Nature, $\mathbf{3 6 5}, 545-548$.

Wolff, J. O. 1985. Behavior. In: Biology of new world Microtus. Special publication No. 8. (Ed. by R. Tamarin), pp. 340-372. Provo: American Society of Mammalogists. 
Wolff, J. O. \& Dunplap, A. S. 2002. Multi-male mating, probability of conception, and litter size in the prairie vole (Microtus ochrogaster). Behavioral Processes, 58, 105-110.

660 Wolff, J. O. \& Macdonald, D. W. 2004. Promiscuous females protect their offspring. Trends in Ecology and Evolution, 19, 127-134.

Wolff, J. O., Mech, S. G., Dunlap, A. S. \& Hodges, K. E. 2002. Multi-male mating by paired and unpaired female prairie voles, Microtus ochrogaster. Behaviour, 139, 1147-1160.

Young, B., Conti, D. V. \& Dean, M. D. 2013. Sneaker “jack” males outcompete dominant 665 "hooknose" males under sperm competition in Chinook salmon (Oncorhynchus tshawytscha). Ecology and Evolution, 3, 4987-4997.

Young, L. J. \& Wang, Z. X. 2004. The neurobiology of pair bonding. Nature Neuroscience, 7, 1048-1054. 
Figure 1

Phase I:

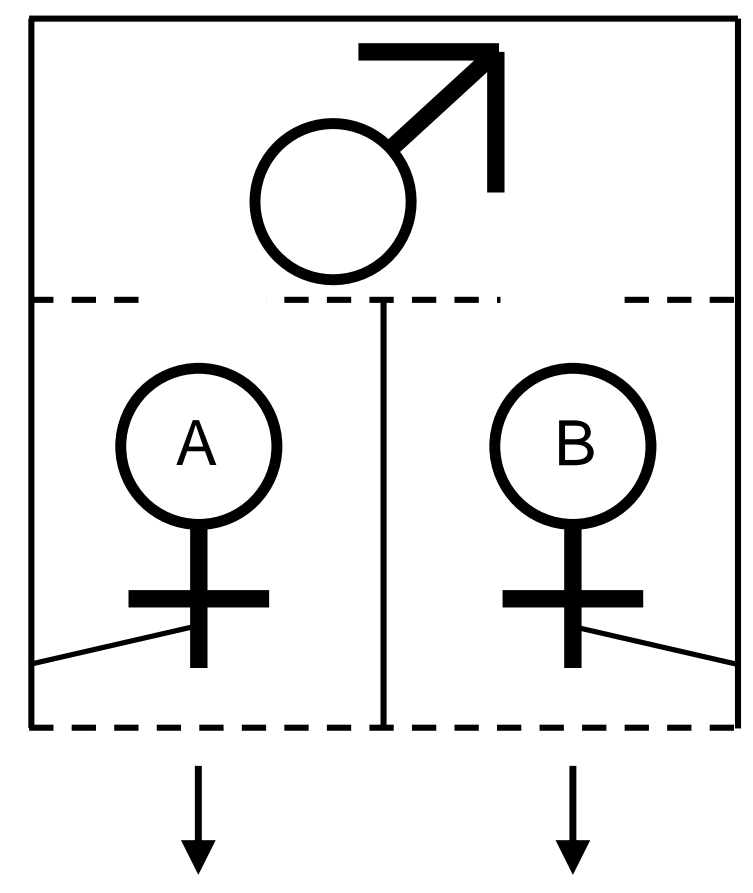

Phase II:
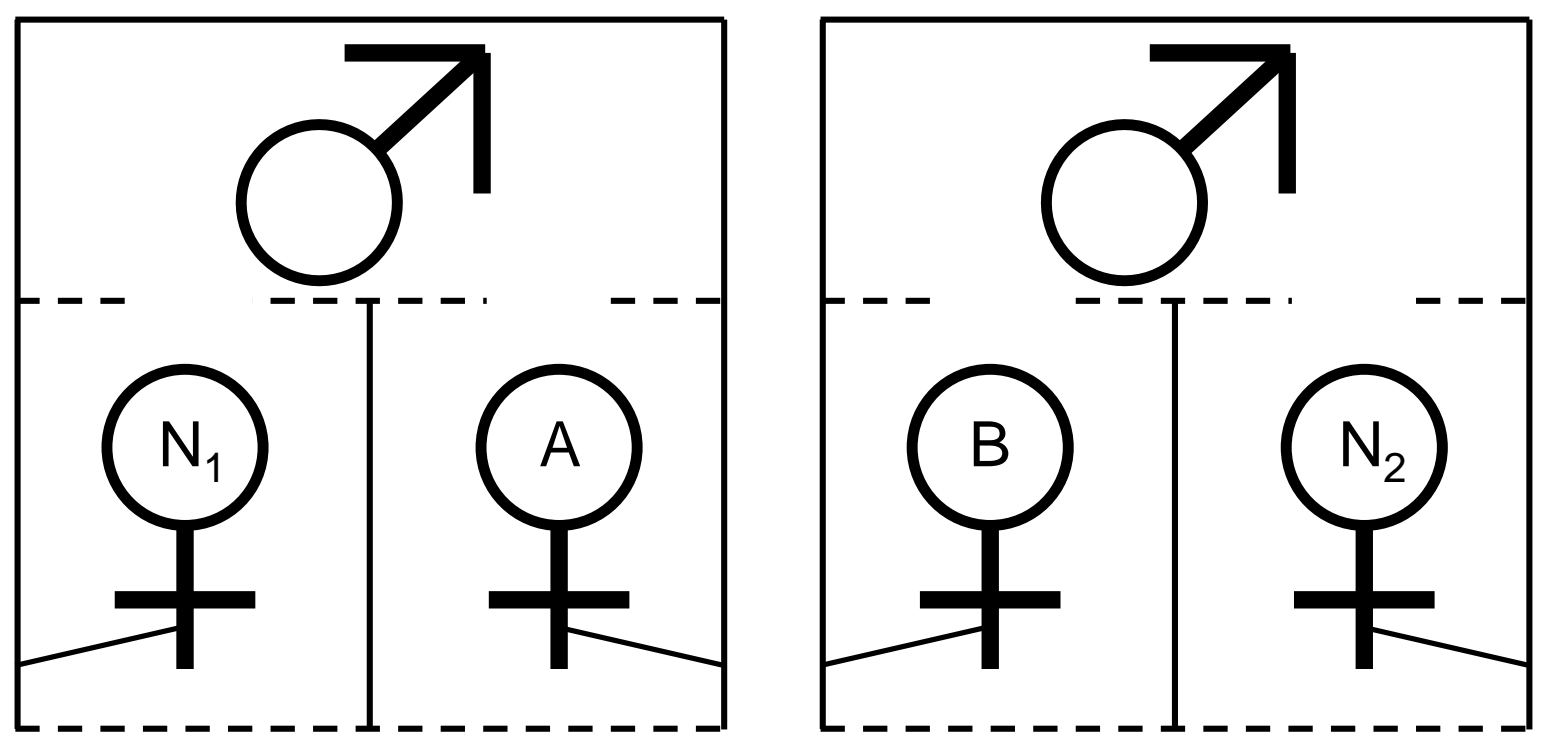
Figure 2

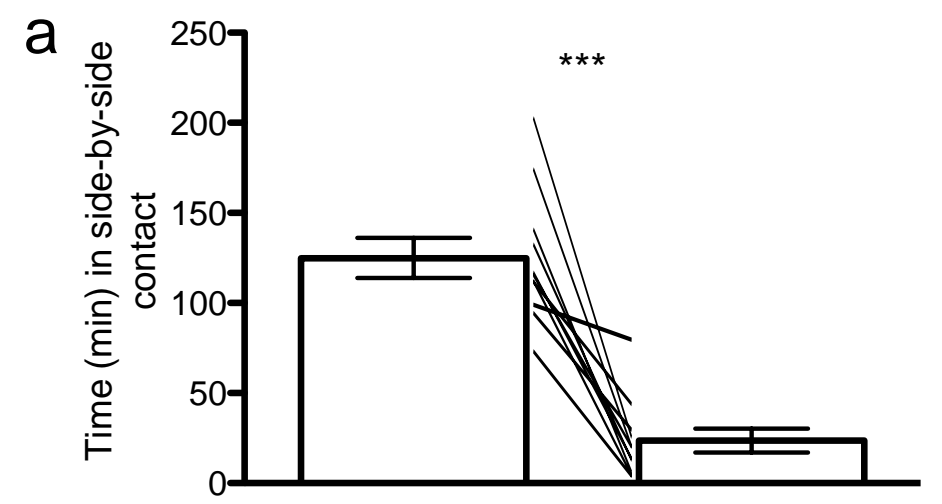

b

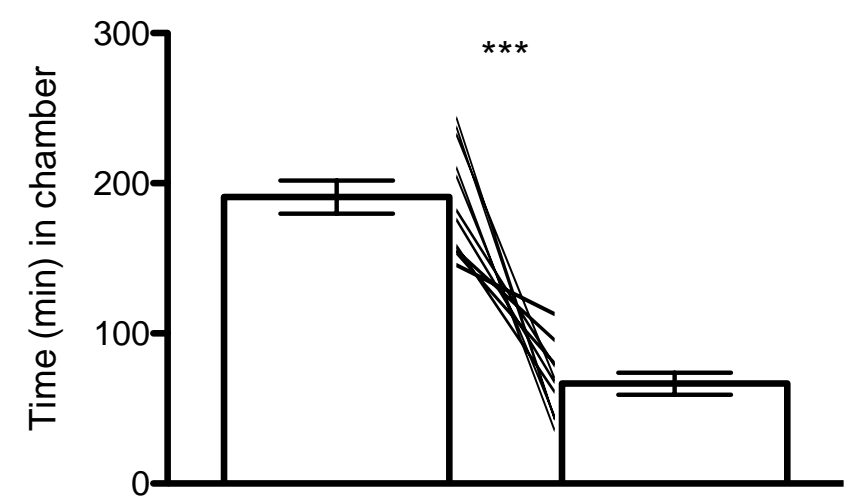

C

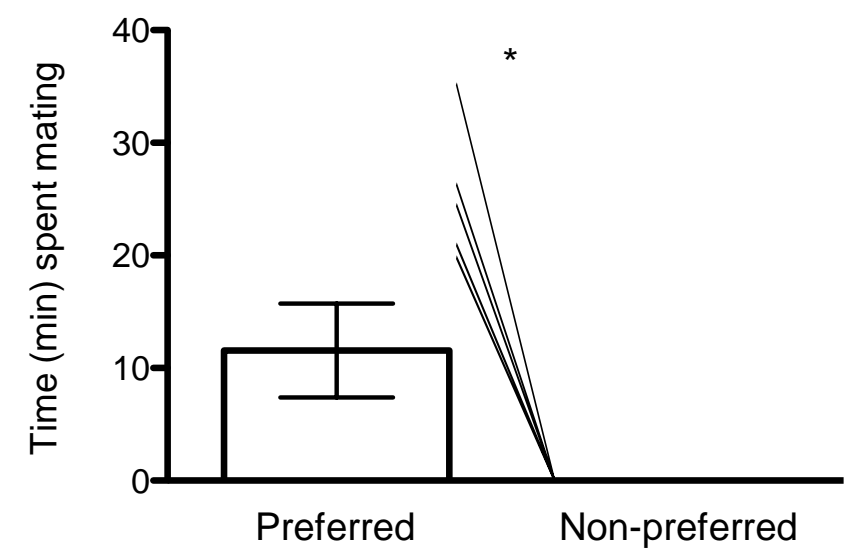


Figure 3
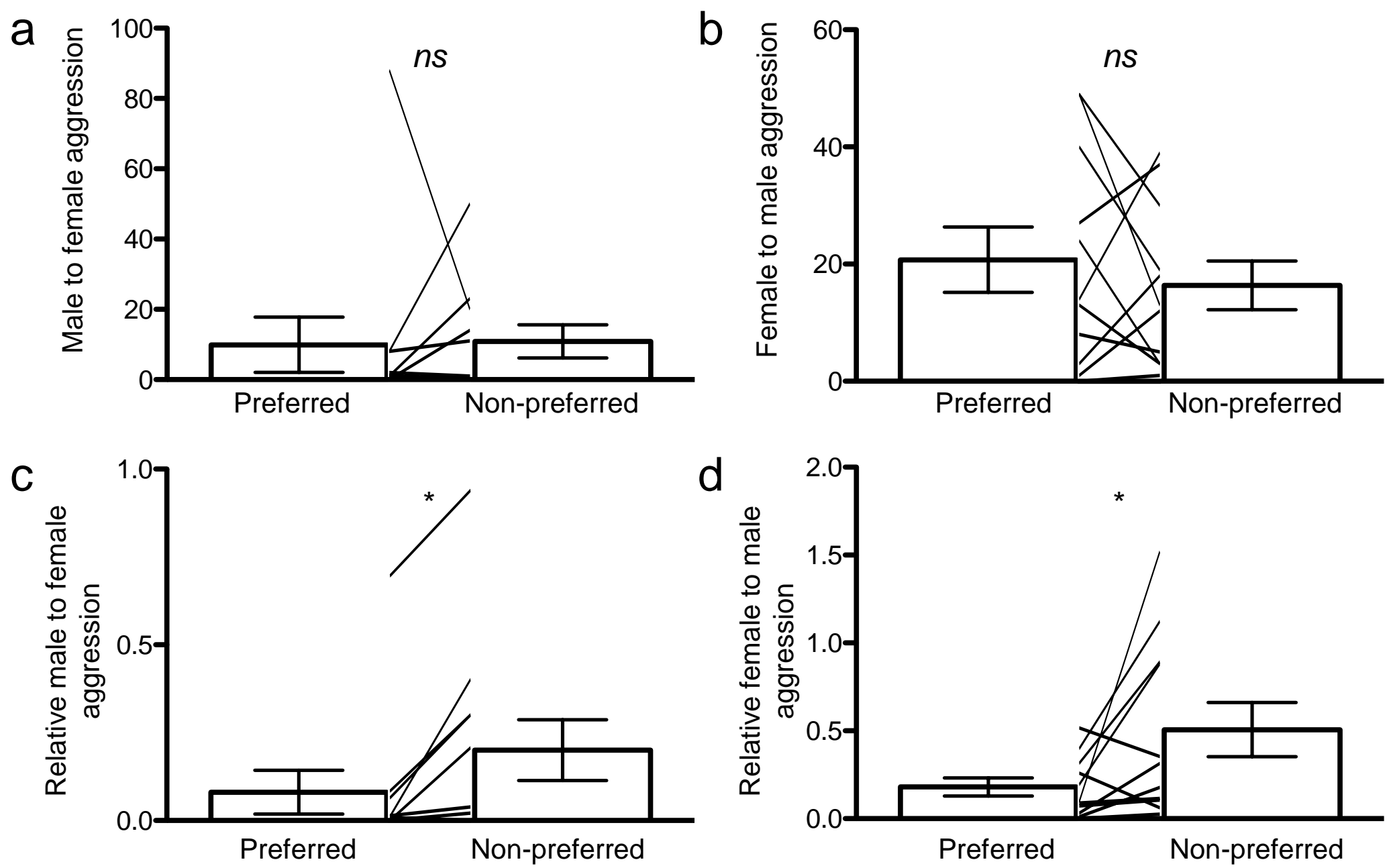
Figure 4
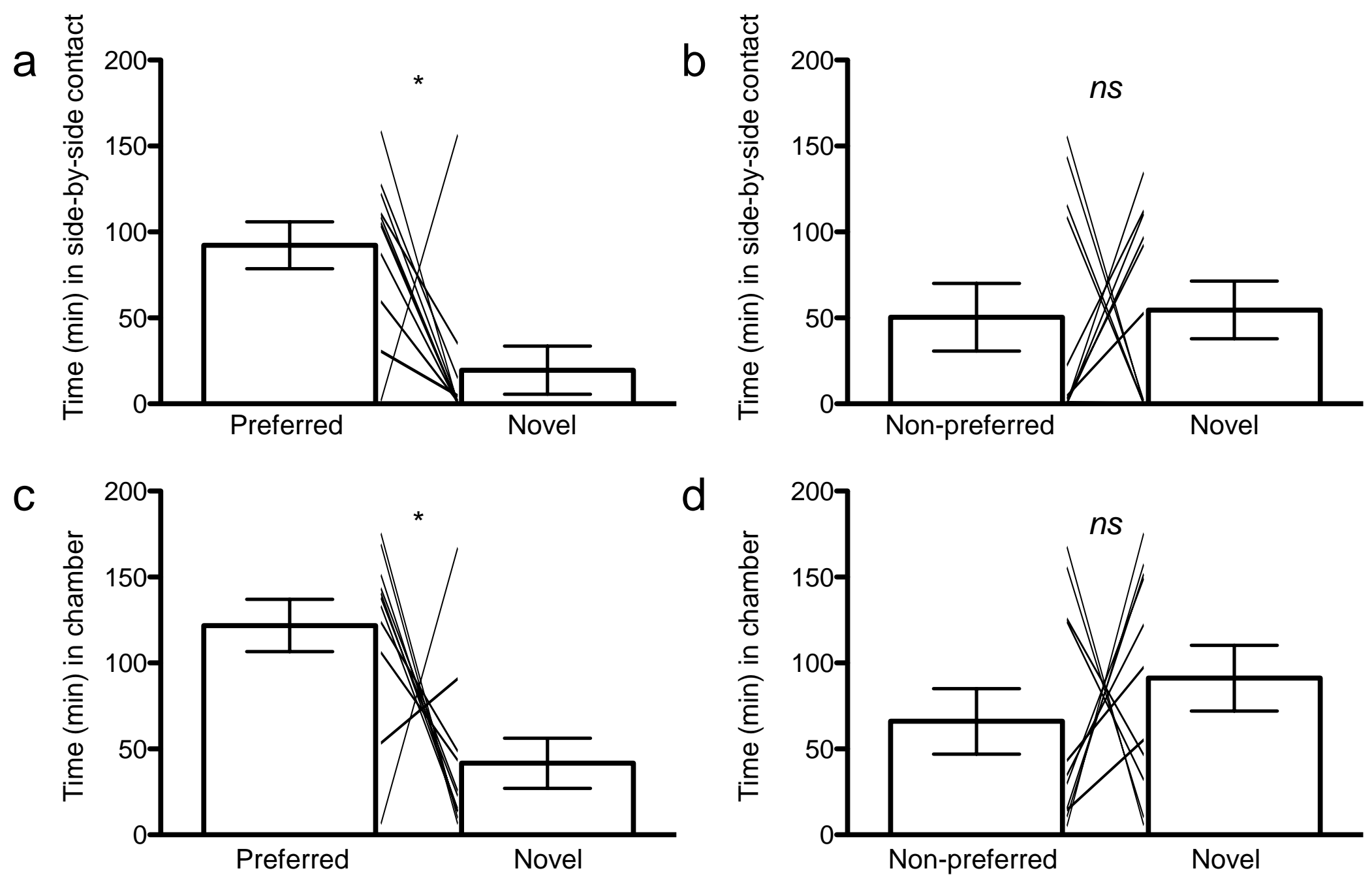
Figure 5
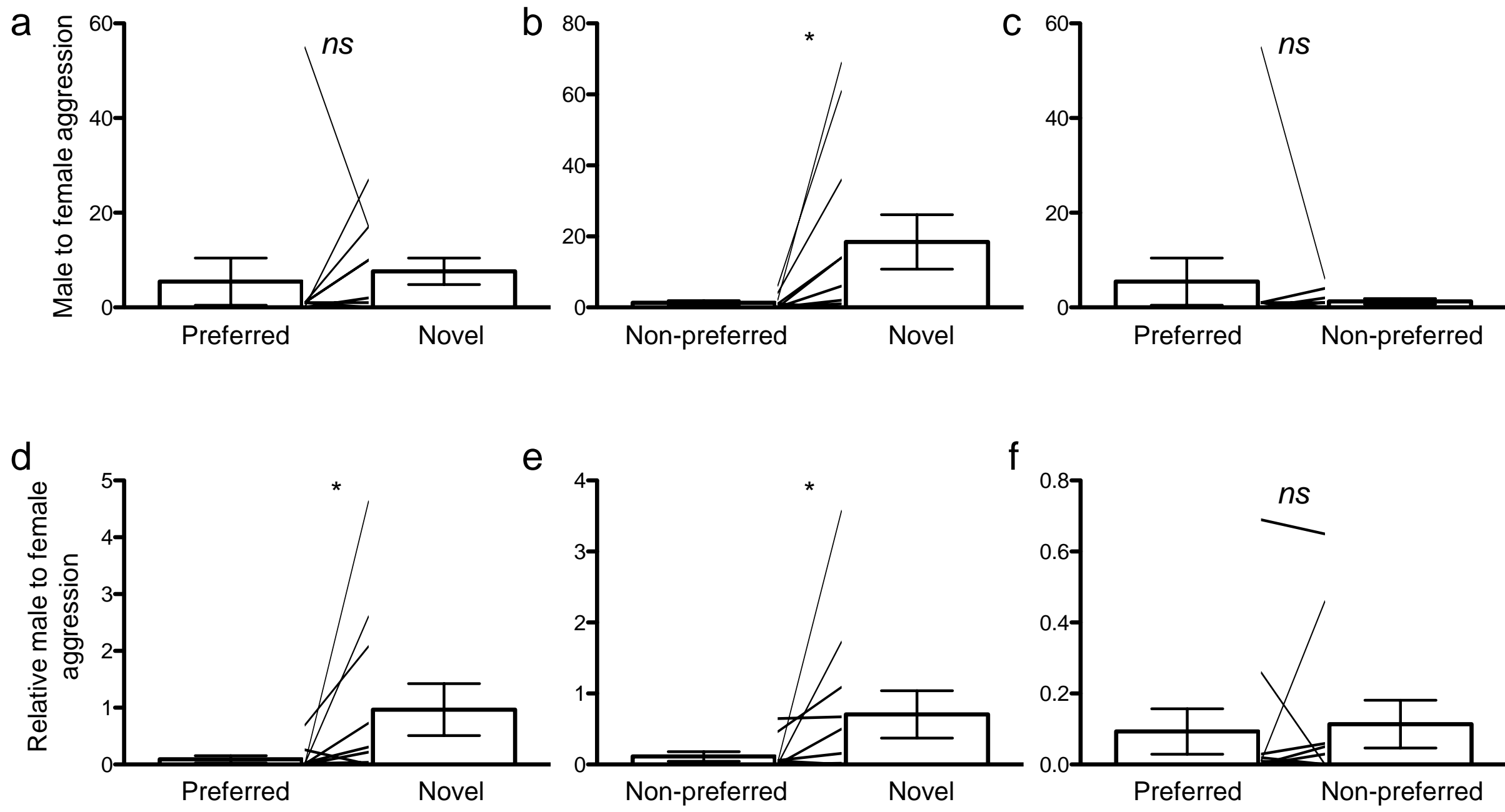
Figure 6

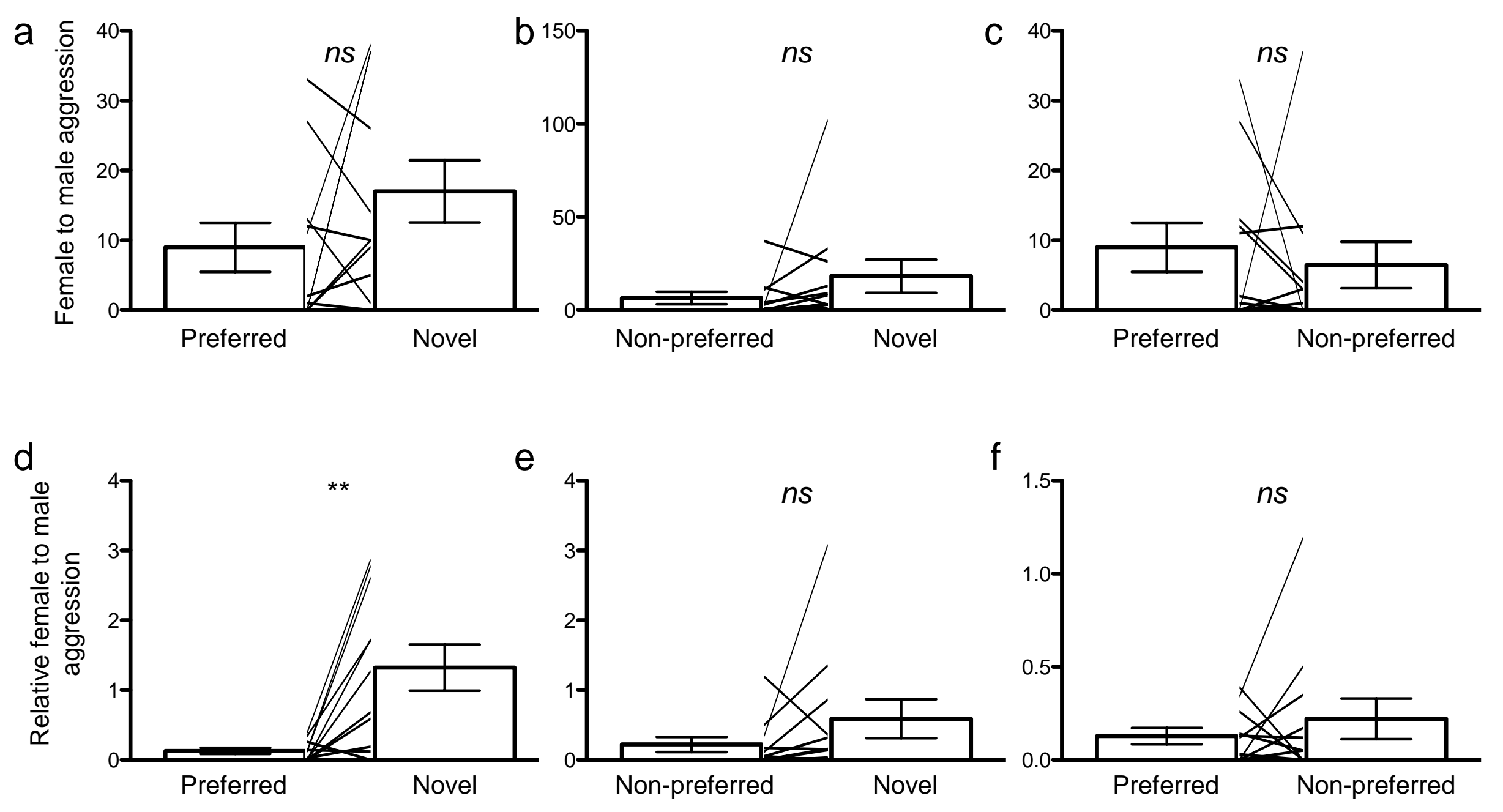

